\title{
A comparison of the hemodynamic changes and propofol- induced pain at two different doses of remifentanil in elderly patients
}

\author{
Sang Hi Park ${ }^{1}$, Soon Taek Jeong ${ }^{1}$, Yang Ju Tak ${ }^{2}$, Chong Soo Kim³ ${ }^{3}$ and Sang Tae Kim ${ }^{1}$ \\ ${ }^{1}$ Department of Anesthesiology and Pain Medicine, College of Medicine, Chungbuk National University, Cheongju, ${ }^{2}$ Department \\ of Emergency Medical Service, Chungju National University, Jeungpyeong, ${ }^{3}$ Department of Anesthesiology and Pain Medicine, \\ Boramae Municipal Hospital, Seoul, Korea
}

Background: The purpose of this study was to determine the optimal dose of remifentanil for minimizing hemodynamic changes during intubation and reducing propofol-induced pain in elderly patients.

Methods: In a randomized prospective study, 60 patients (ASA I-II, elder than 65 years) were enrolled to determine which of two target remifentanil blood concentrations $(3 \mathrm{ng} / \mathrm{ml}, 5 \mathrm{ng} / \mathrm{ml}$ ) was required to blunt hemodynamic changes during intubation and to reduce propofol-induced pain. After the target effect site concentration of remifentanil had been reached, the target controlled infusion of propofol was started and propofol-induced pain was recorded. Blood pressure and heart rate were recorded at baseline, just before intubation and 1, 3, 5 min after intubation.

Results: There were no significant differences in the hemodynamic parameters between two groups, but not in arterial pressure at just before intubation and 1 minute after intubation. However, the group R5 (5 ng/ml) showed significantly less intense pain induced by propofol than in the group R3 (3 ng/ml).

Conclusions: The results suggest that the group R5 provide more relief in propofol induced pain than the group R3, but showed great possibility of hypotension and bradycardia in both groups, which means it should be used with cautions in the elderly patients. (Korean J Anesthesiol 2010; 58: 532-536)

Key Words: Blood pressure, Heart rate, Propofol, Remifentanil.

Received: February 11, 2010. Revised: 1st, February 26, 2010; 2nd, March 19, 2010. Accepted: April 14, 2010.

Corresponding author: Sang Tae Kim, M.D., Department of Anesthesiology and Pain Medicine, College of Medicine, Chungbuk National University, Gaesin-dong, Heungdeok-gu, Cheongju 361-711, Korea. Tel: 82-43-269-6237, Fax: 82-43-272-0264, E-mail: kimst@chungbuk.ac.kr This is a theisis for a master's degree.

(c) This is an open-access article distributed under the terms of the Creative Commons Attribution Non-Commercial License (http:// creativecommons.org/licenses/by-nc/3.0/), which permits unrestricted non-commercial use, distribution, and reproduction in any medium, provided the original work is properly cited. 


\section{Introduction}

As aging progresses, there is more stiffness of the heart and blood vessels, a decrease in stimulus to the beta-adrenergic receptor, unbalance and disorder of the autonomic nerve system, and changes in the conduction system. Therefore, the morbidity rate caused by cardiovascular diseases increases, and the hemodynamic changes to the stimuli can happen frequently and severely. An older person has a sensitive response to intravenous anesthetics such as propofol and lowered clearance, so he or she becomes $30-50 \%$ more sensitive to propofol. The same happens with opioid analgesics, and the duration of drug action lengthens because of the decrease in clearance. Therefore, it is more predictable and appropriate to inject drugs of short context-sensitive half-life, such as remifentanil. For temporary intravenous injections as well as constant injection, the changes in pharmacokinetics of remifentanil are much fewer than other opioid analgesics; remifentanil is recommended as the opioid analgesics to anesthetize an older person [1]. In addition, as endo-tracheal intubation itself may induce harmful hemodynamic changes such as the increase in blood pressure and heart rate, arrhythmia and myocardial ischemia [2]. For elderly patients, it is important to set an adequate remifentanil control level to minimize the hemodynamic change caused by the intubation and to decrease the pain due to intravenous injection, which is the side effect of propofol.

This study intends to clarify the adequate effect-site concentration of remifentanil at the propofol effect-site concentration of $4 \mu \mathrm{g} / \mathrm{ml}$ when the propofol-remifentanil total intravenous anesthesia was induced for elderly patients.

\section{Materials and Methods}

Sixty ASA I or II patients over the age 65 and regardless of sex, who are undergoing regular surgery, were randomly selected. This study has gotten the permission of the Clinical Ethics Committee of our hospital and the agreement of the patients after a full explanation of the purpose and method of the study beforehand. Among the target patients, patients over the Mallampati classification III were excluded from the study, and the cases that have two or more trials of endo-tracheal intubation were also excluded.

The sixty patients were randomized into two groups, and they were given remifentanil $3 \mathrm{ng} / \mathrm{ml}$ (R3 group, $\mathrm{n}=30$ ) or $5 \mathrm{ng} / \mathrm{ml}$ (R5 group, $\mathrm{n}=30$ ). No patients had received premedication before their arrival in the operating room. Electrocardiography, non-invasive blood pressure monitor and pulse oximeter were attached to the patients when they arrived at the operating room. For the anesthesia, target controlled infusion via syringe pump (Orchestra ${ }^{\circledR}$, Fresenius Vial, France) was used to induce the propofol-remifentanil total intravenous anesthesia. When remifentanil reached the pre-set concentration, propofol was injected into the effect-site concentration of $4 \mu \mathrm{g} / \mathrm{ml}$. After unconsciousness was confirmed, the intravenous injection of vecuronium $0.15 \mathrm{mg} / \mathrm{kg}$ was administered; after 3 minutes, the intubation was performed.

Before the intubation, the Mallampati classification was recorded for the airway evaluation, the Cormack and Lehane grade and the POGO (percentage of glottic opening) score were recorded for the airway evaluation.

In order to compare the side effects right after the injection of remifentanil, we checked for coughing, vertigo, and chest pain. After remifentanil reached the pre-set concentration, the intravenous injection of propofol began and the degree of pain felt by the patients in the injected part was observed with the four-point verbal categorical scoring system used by King et al. [3] through facial expression, tears, withdrawal behavior, screaming, and complaining of pain. Responses were classified into four categories: there were no unpleasant feelings (none), no facial expression of pain but reported feelings of pain when asked (mild), no frown or withdrawal response but complaints of pain (moderate) and the existence of tears, and frown and withdrawal response (severe).

Blood pressure and heart rate were measured upon arrival at the operation room, just before the intubation, and after 1 minute, 3 minutes, and 5 minutes of intubation; the measurement upon arrival at the operation room was set as the baseline. The parameters between the two groups were compared and within the same group, the changes in blood pressure and heart rate just before intubation, after 1 minute, 3 minutes and 5 minutes of intubation were compared with the baseline.

There was a study about the frequency of pain after the intravenous injection of propofol and after the premedication of remifentanil; the frequency was $51 \%$. In this study for elderly patients, the frequency of pain after the intravenous injection of propofol was expected to be $20 \%$ and the number of meaningful samples were calculated with $80 \%$ power and the two-sided type I error $=0.05$, and the result is 30 . The number of target samples was set at 30 patients per group. All the measurements were marked as mean \pm standard deviation, and SPSS (version 12.0, SPSS Inc, Chicago, USA) was used for statistical analysis. Chi-square test was used for inter-group comparison of gender. Unpaired T test was used to compare age, height, weight and the measurement between the two groups in time. Paired T test was used to compare the measurement within the same group. A P value under 0.05 was determined as statistically significant.

\section{Results}

There was no significant difference in the age, sex, height 
and weight between the two groups (Table 1), and there was also no significant difference in the Mallampati classification, the Cormack and Lehane grade, the POGO score, and the intubation time (Table 2).

Among the side effects of the injection of remifentanil between the two groups, the frequency of coughing significant increased in the R5 group and the others had no significant

Table 1. Demographic Data

\begin{tabular}{lcc}
\hline \multicolumn{1}{c}{ Group } & $\mathrm{R} 3(\mathrm{n}=30)$ & $\mathrm{R} 5(\mathrm{n}=30)$ \\
\hline Age (year) & $70.4 \pm 4.9$ & $68.4 \pm 2.8$ \\
& (From 65 to 83) & (From 65 to 74) \\
Weight (kg) & $59.9 \pm 8.4$ & $58.8 \pm 7.8$ \\
Height (cm) & $157.8 \pm 8.3$ & $157.2 \pm 9.2$ \\
Gender (M/F) & $16 / 14$ & $16 / 14$ \\
ASA I/II & $13 / 17$ & $17 / 13$ \\
Hypertension & 12 & 12 \\
Heart disease & 0 & 1 \\
Cerebrovascular disease & 1 & 0 \\
\hline
\end{tabular}

Values are number of patients or mean \pm SD. R3: effect site concentration of remifentanil $3 \mathrm{ng} / \mathrm{ml}$, R5: effect site concentration of remifentanil $5 \mathrm{ng} / \mathrm{ml}$.

Table 2. Laryngeal View and Intubation Time

\begin{tabular}{lccc}
\hline \multicolumn{1}{c}{ Group } & & $\mathrm{R} 3(\mathrm{n}=30)$ & $\mathrm{R} 5(\mathrm{n}=30)$ \\
\hline Mallampati classification & $\mathrm{I}$ & 18 & 20 \\
& $\mathrm{II}$ & 12 & 10 \\
Cormack and Lehane grade & 1 & 22 & 28 \\
& 2 & 8 & 2 \\
POGO score & & $55.7 \pm 41.2$ & $62.0 \pm 29.0$ \\
Intubation time (sec) & & $14.6 \pm 7.4$ & $11.9 \pm 3.6$
\end{tabular}

Values are number of patients or mean \pm SD. Mallampati classification: I: full visibility of tonsils, uvula and soft palate, II: visibility of hard and soft palate, upper portion of tonsils and uvula. Cormack and Lehane grade 1: visualization of entire laryngeal aperture, 2: visualization of just the posterior portion of laryngeal aperture. POGO score: Represents the linear span extending from the anterior commissure to the interarytenoid notch of the vocal cords. R3: effect site concentration of remifentanil $3 \mathrm{ng} / \mathrm{ml}$, R5: effect site concentration of remifentanil $5 \mathrm{ng} / \mathrm{ml}$. difference (Table 3). Concerning the injection of propofol, in the R3 group, 3 patients complained of severe pain, 7 moderate, and 13 mild, while in the R5 group there was just 1 moderate complaint and 6 mild; the difference was significant (Table 4).

When we compare the two groups, the systolic arterial pressure just before intubation meaningfully decreased in the R5 group, and after 1 minute of intubation, the systolic and diastolic arterial pressure excluding the heart rate were meaningfully lowered in the R5 group than the R3 group. The hemodynamic parameters on 3 minutes and 5 minutes after intubation of the two groups had no significant difference. Within the R3 group, all the hemodynamic parameters just before intubation, 3 minutes and 5 minutes after intubation- excluding 1 minute after the intubation-had significantly differed from the status before the anesthesia; within the R5 group, all the hemodynamic parameters, excluding the heart rate after 1 minute of the intubation, had significant difference from the status before the anesthesia (Table 5).

Table 3. Incidence of Complications on Remifentanil

\begin{tabular}{lcc}
\hline \multicolumn{1}{c}{ Group } & $\mathrm{R} 3(\mathrm{n}=30)$ & $\mathrm{R} 5(\mathrm{n}=30)$ \\
\hline Cough & 0 & $4^{*}$ \\
Chest tightness & 0 & 0 \\
Dizziness & 19 & 19 \\
\hline
\end{tabular}

Values are number of patients. R3: effect site concentration of remifentanil $3 \mathrm{ng} / \mathrm{ml}$, R5: effect site concentration of remifentanil $5 \mathrm{ng} /$ ml. *P $<0.05$ compared with $\mathrm{R} 3$.

Table 4. Pain on Injection of Propofol

\begin{tabular}{lcc}
\hline & $\mathrm{R} 3(\mathrm{n}=30)$ & $\mathrm{R} 5(\mathrm{n}=30)^{*}$ \\
\hline None & 7 & 23 \\
Mild & 13 & 6 \\
Moderate & 7 & 1 \\
Severe & 3 & 0 \\
\hline
\end{tabular}

Values are number of patients. R3: effect site concentration of remifentanil $3 \mathrm{ng} / \mathrm{ml}$, R5: effect site concentration of remifentanil $5 \mathrm{ng} /$ $\mathrm{ml} .{ }^{*} \mathrm{P}<0.05$ compared with $\mathrm{R} 3$.

Table 5. Hemodynamic Changes

\begin{tabular}{|c|c|c|c|c|c|c|}
\hline & & Baseline & Preintubation & A1 & A3 & A5 \\
\hline \multirow[t]{2}{*}{ HR (beats/min) } & R3 & $74 \pm 12.6$ & $62 \pm 9.8^{\dagger}$ & $76 \pm 13.4$ & $65 \pm 11.0^{\dagger}$ & $61 \pm 11.1^{\dagger}$ \\
\hline & R5 & $75 \pm 13.2$ & $59 \pm 6.7^{\dagger}$ & $73 \pm 12.6$ & $65 \pm 10.2^{\dagger}$ & $62 \pm 10.3^{\dagger}$ \\
\hline \multirow[t]{2}{*}{ SAP (mmHg) } & R3 & $141 \pm 15.7$ & $97 \pm 17.7^{\dagger}$ & $131 \pm 25.2$ & $107 \pm 19.1^{\dagger}$ & $95 \pm 14.0^{\dagger}$ \\
\hline & R5 & $148 \pm 18.9$ & $87 \pm 18.3^{*, \dagger}$ & $107 \pm 18.3^{*, \dagger}$ & $98 \pm 16.2^{\dagger}$ & $94 \pm 15.2^{\dagger}$ \\
\hline \multirow[t]{2}{*}{ DAP (mmHg) } & R3 & $84 \pm 9.4$ & $57 \pm 8.3^{\dagger}$ & $81 \pm 14.7$ & $64 \pm 11.2^{\dagger}$ & $59 \pm 8.9^{\dagger}$ \\
\hline & R5 & $88 \pm 9.6$ & $54 \pm 10.2^{\dagger}$ & $70 \pm 14.9^{*, \dagger}$ & $62 \pm 9.8^{\dagger}$ & $59 \pm 11.4^{\dagger}$ \\
\hline \multirow[t]{2}{*}{ MAP (mmHg) } & R3 & $104 \pm 21.8$ & $75 \pm 20.4^{\dagger}$ & $101 \pm 19.0$ & $81 \pm 12.4^{\dagger}$ & $73 \pm 10.1^{\dagger}$ \\
\hline & R5 & $115 \pm 13.4^{*}$ & $67 \pm 13.8^{\dagger}$ & $86 \pm 17.8^{*, \dagger}$ & $76 \pm 12.4^{\dagger}$ & $73 \pm 12.8^{\dagger}$ \\
\hline
\end{tabular}

Values are mean \pm SD. HR: heart rate, SAP: systolic arterial pressure, DAP: diastolic arterial pressure, MAP: mean arterial pressure, Preintubation: just before insertion of laryngoscope, A1, A3 and A5: 1, 3 and 5 minutes after intubation. R3: effect site concentration of remifentanil 3 ng/ $\mathrm{ml}$, R5: effect site concentration of remifentanil $5 \mathrm{ng} / \mathrm{ml} . * \mathrm{P}<0.05$ compared with $\mathrm{R} 3,{ }^{\dagger} \mathrm{P}<0.05$ compared with baseline. 


\section{Discussion}

It is important to choose the appropriate anesthetic agent and to inject the right dose for elderly patients since it is probable they have severe hemodynamic changes in anesthesia because of their physiological changes accompanying aging and aging-involved diseases; even a little dose may provoke sensitive medical action. It is essential to find out the adequate inspired concentration in order to minimize the depression of the cardiovascular system and to maintain intra-operative narcohypnosis when propofol is intravenously injected for the induction and maintenance of anesthesia for an older person. A study reported that $4 \mu \mathrm{g} / \mathrm{ml}$ of propofol concentration might induce adequate unconsciousness for $90 \%$ of the patients when adults were induced by anesthesia [4,5], and recent studies report that the propofol concentration to maintain the BIS value as $40-50$ should be $3.4 \mu \mathrm{g} / \mathrm{ml}, 3.5 \mu \mathrm{g} / \mathrm{ml}$ and $3.75 \mu \mathrm{g} / \mathrm{ml}$ [6-8]. In this study, the effect-site concentration of propofol was set as $4 \mu \mathrm{g} / \mathrm{ml}$ based on the above results.

According to previous reports, the pain around the injected part frequently happened, $30-70 \%$, when propofol was injected [9]; although the exact cause of the pain has not been clarified, a study reported that it might be because propofol itself irritates the arterial wall and activates kinin cascade [10]. Another study reported the correlation between the concentration of the emulsion and the degree of pain [11]. In order to decrease the pain, various studies are now being performed; recently, methods like the injection through a blood vessel with a large diameter, the premedication of drugs such as opioid analgesic, NSAID (non-steroidal anti-inflammatory drugs) or local anesthetic agent, and the injection of diluted or lowtemperature propofol itself are being used [10-15].

This study intended to find out the adequate inspired concentration of remifentanil without any other premedication to control the pain caused by the intravenous injection of propofol as well as to restrain the hemodynamic changes caused by intubation, only by controlling the concentration of remifentanil.

In a similar study regarding total intravenous anesthesia using propofol and remifentanil in cases of eldery patients, Xu et al. [16] reported that both remifentanil effect-site concentration $4 \mathrm{ng} / \mathrm{ml}$ and $7 \mathrm{ng} / \mathrm{ml}$ blocked the response from the endotracheal intubation, but $7 \mathrm{ng} / \mathrm{ml}$ had a high probability of hypotension; therefore $4 \mathrm{ng} / \mathrm{ml}$ was recommended. Park et al. [17] effectively restrained the hemodynamic changes at the remifentanil effect-site concentration of $2 \mathrm{ng} / \mathrm{ml}$. However, at 4 $\mathrm{ng} / \mathrm{ml}$ there was severe bradycardia and hypotension, so $2 \mathrm{ng} /$ $\mathrm{ml}$ dose should be adequate. In addition, Tak et al. [18] found that the doses of remifentanil effect-site concentration $1 \mathrm{ng} / \mathrm{ml}$ and $3 \mathrm{ng} / \mathrm{ml}$ had a similar risk of hypotension, and the dose of 3 $\mathrm{ng} / \mathrm{ml}$ effectively restrained the changes of heart rate and blood pressure after intubation, decreasing the pain. In the studies where the target was not the elderly patients but other younger adult patients, Albertin et al. [6] reported that the adequate concentration needed to relax the sympathetic nerve system for intubation in order to induce anesthesia was remifentanil 5 ng/ml. According to Kim et al. [19], the adequate remifentanil effect-site concentration for the intubation was 3 or $4 \mathrm{ng} / \mathrm{ml}$.

In regards to the total intravenous anesthesia, the adequate remifentanil effect-site concentration to block hemodynamic changes caused by intubation was largely affected by the concentration of propofol that was simultaneously injected. Because of their mutual synergism, the effect-site concentration of remifentanil may be lower or higher depending on the level of propofol concentration, Most studies sought to find the adequate remifentanil effect-site concentration based on propofol 3-4 $\mu \mathrm{g} / \mathrm{ml}$; however, Park et al. [17] recommended remifentanil $2 \mathrm{ng} / \mathrm{ml}$; it is inferred that this is because their propofol effect-site target concentration was $5.4 \mu \mathrm{g} / \mathrm{ml}$.

In the previous studies, the prevalent opinions are that the remifentanil concentration $2-4 \mathrm{ng} / \mathrm{ml}$ for elderly patients and $3-5 \mathrm{ng} / \mathrm{ml}$ for adult patients should be adequate. Thereby in this study, the effect-site concentration of propofol was set to 4 $\mu \mathrm{g} / \mathrm{ml}$, the concentration of remifentanil was set to 3 and $5 \mathrm{ng} /$ $\mathrm{ml}$, and 60 members were randomized into two groups. The original plan was to study 3 groups of 30 members each with 3 , 5 and $7 \mathrm{ng} / \mathrm{ml}$ as well as high concentration, However, among 7 patients of $7 \mathrm{ng} / \mathrm{ml}, 5$ patients showed bradycardia with no response to atropine, and there was constant hypotension in spite of two or more injections of ephedrine. There is a report that the comparison of the injection of remifentanil 5, 10 and $15 \mathrm{ng} / \mathrm{ml}$ showed a decrease of the cough response in $75 \%$. At least at $10 \mathrm{ng} / \mathrm{ml}$, the response caused by the endo-tracheal intubation was properly lowered the most [20]; however, many elderly patients have high blood pressure as an underlying disease even if they are ASA I, II, and they show different responses to the stimuli of blood vessels and the receptors because of their age; the highly-concentrated remifentanil was judged to be inadequate.

In this study, the survey of the two groups, the group of $3 \mathrm{ng} /$ $\mathrm{ml}$ and $5 \mathrm{ng} / \mathrm{ml}$, illustrates that the duration and the frequency of intubation had no difference, and the cough response caused by endo-tracheal suctioning never happened since the survey was performed after the injection of the muscle relaxant. In the inter-group comparison, the systolic arterial pressure just before the intubation and 1 minute after intubation had meaningful difference, and there was a decrease in the R5 group. In both groups, blood pressure and heart rate decreased just before intubation and 3 and 5 minutes after intubation than the baseline; the blood pressure after 1 minute was also 
meaningfully lower than the baseline in the R5 group, but had no difference in the R3 group; in both groups the hemodynamic changes due to intubation can effectively be restrained. Rather, in the R5 group, blood pressure and heart rate decreased with a great difference from the baseline, and therefore it might be relatively high concentration for elderly patients. However, in cases where propofol was injected after remifentanil reached 3 or $5 \mathrm{ng} / \mathrm{ml}$, more than half of the R3 group complained of pain, but the R5 group complained of mild pain or had no pain. For the premedication to suppress the pain of the intravenous injection of propofol, remifentanil $3 \mathrm{ng} / \mathrm{ml}$ seems to be insufficient and $5 \mathrm{ng} / \mathrm{ml}$ adequate.

As for the above results, it may be good news for elderly patients if the first remifentanil concentration is set to $5 \mathrm{ng} / \mathrm{ml}$ to decrease the pain of the intravenous injection of propofol and after unconsciousness, it should be lowered to $3 \mathrm{ng} / \mathrm{ml}$ to protect hypotension and bradycardia. However, elderly patients have great differences in sensitivity to anesthetic agents according to the morbidity rate or to the body index; therefore careful observation is needed when using more than remifentanil $3 \mathrm{ng} / \mathrm{ml}$ for elderly patients since they have high frequency and degree of hypotension. Further study of remifentanil concentration of 1,2 and $3 \mathrm{ng} / \mathrm{ml}$ for elderly patients can produce more valuable results.

\section{References}

1. Sieber FE, Pauldine R. Geriatric anesthesia. In: Miller's anesthesia. 7th ed. Edited by Miller RD: Philadelphia, Churchill Livingstone. 2010, pp 2261-76.

2. Zbinden AM, Petersen-Felix S, Thomson DA. Anesthetic depth defined using multiple noxious stimuli during isoflurane/oxygen anesthesia. II. Hemodynamic responses. Anesthesiology 1994; 80: 261-7.

3. King SY, Davis FM, Wells JE, Murchison DJ, Pryor PJ. Lidocaine for the prevention of pain due to injection of propofol. Anesth Analg 1992; 74: 246-9.

4. Smith C, McEwan AI, Jhaveri R, Wilkinson M, Goodman D, Smith LR, et al. The interaction of fentanyl on the Cp50 of propofol for loss of consciousness and skin incision. Anesthesiology 1994; 81: 820-8.

5. Vuyk J, Engbers FH, Burm AG, Vletter AA, Griever GE, Olofsen E, et al. Pharmacodynamic interaction between propofol and alfentanil when given for induction of anesthesia. Anesthesiology 1996; 84: 288-99.
6. Albertin A, Casati A, Federica L, Roberto V, Travaglini V, Bergonzi $\mathrm{P}$, et al. The effect-site concentration of remifentanil blunting cardiovascular responses to tracheal intubation and skin incision during bispectral index-guided propofol anesthesia. Anesth Analg 2005; 101: 125-30.

7. Kil HY, Lee SI, Lee SJ, Lee SW, Lee DH. The bispectral index and modified observer's assessment of alertness/sedation scale comparable to effect site concentration of propofol in Koreans. Korean J Anesthesiol 2000; 38: 251-7.

8. Munoz HR, Cortinez LI, Ibacache ME, Leon PJ. Effect site concentrations of propofol producing hypnosis in children and adults: Comparison using the bispectral index. Acta Anaesth Scand 2006; 50: 882-7.

9. Picard P, Tramer MR. Prevention of pain on injection with propofol: a quantitative systematic review. Anesth Analg 2000; 90: 963-9.

10. Scott RP, Saunders DA, Norman J. Propofol: clinical strategies for preventing the pain of injection. Anaesthesia 1988; 43: 492-4.

11. Klement W, Arndt JO. Pain on injection of propofol: effects of concentration and diluent. Br J Anaesth 1991; 67: 281-4.

12. Fletcher JE, Seavell CR, Bowen DJ. Pretreatment with alfentanil reduces pain caused by propofol. Br J Anaesth 1994; 72: 342-4.

13. Gehan G, Karoubi P, Quinet F, Leroy A, Rathat C, Pourriat JL. Optimal dose of lignocaine for preventing pain on injection of propofol. Br J Anaesth 1991; 66: 324-6.

14. Smith AJ, Power I. The effect of pretreatment with ketorolac on pain during intravenous injection of propofol. Anaesthesia 1996; 51: 883-5.

15. Park CJ, Choi JS, Lee CS, Kim WT. Effect of cooling and lidocaine on propofol induced vascular pain. Korean J Anesthesiol 1993; 26: 266 71.

16. Xu CY, Wu XM, Jiang JY. Target-controlled infusions of remifentanil and propofol in elderly patients. Beijing Da Xue Xue Bao 2005; 37: 513-5.

17. Park KS, Kim JY, Chae YJ, Min SK, Moon BK. Hemodynamic responses according to different effect site concentration of remifentanil during endotracheal intubation. Intrav Anesth 2005; 9: 191-6.

18. Tak YJ, Shin HJ, Kim ES, Koo BW, Shin YD, Kim ST. What is the optimal effect-site concentration of remifentanil for minimizing the cardiovascular changes to endotracheal intubation during induction with propofol in elderly patients? Korean J Anesthesiol 2009; 56: 392-7.

19. Kim SK, Kim DK, Son JS, Ko SH, Lee JR. What is the optimal effectsite concentration of remifentanil for minimizing the cardiovascular changes to endotracheal intubation during induction with propofol? Korean J Anesthesiol 2008; 54: 30-6.

20. Leone M, Rousseau S, Avidan M, Delmas A, Viviand X, Guyot L, et al. Target concentrations of remifentanil with propofol to blunt coughing during intubation, cuff inflation, and tracheal suctioning. Br J Anaesth 2004; 93: 660-3. 